\title{
APRENDER A RESOLVER PROBLEMAS: ABORDAGEM PARA A FORMAÇÃO INICIAL DE PROFESSORES
}

\author{
LEARNING TO SOLVE PROBLEMS: APPROACH TO INITIAL \\ TEACHER TRAINING
}

\section{APRENDER A RESOLVER PROBLEMAS: ENFOQUE PARA LA FORMACIÓN INICIAL DE PROFESORES}

Sidinei Oliveira Sousa ${ }^{1}$ ${ }^{1}$ Universidade do Oeste Paulista (UNOESTE), Presidente Prudente/SP-Brasil

RESUMo Este estudo tem como objetivo investigar a abordagem metodológica da Aprendizagem Baseada em Problemas e Organizada em Projetos que combinam atividades online e presenciais (Blended Learning) para promover habilidades de resolução de problemas na formação inicial de professores por meio das Tecnologias Digitais de Informação e Comunicação (TDIC). Para atender a esse objetivo, foi desenvolvido um estudo de caráter qualitativo, mediante uma pesquisa do tipo intervenção, que analisou os fenômenos que ocorreram com a implantação da abordagem Blended Online POPBL (Project Organized and Problem Based Learning) como estratégia pedagógica em uma disciplina de "Introdução à Computação" no primeiro ano de um curso de licenciatura em Química. Para o levantamento dos dados, foram consideradas as interações online, autoavaliações, relatórios, projetos desenvolvidos e questionários. A análise dos dados evidenciou que a abordagem Blended Online POPBL mostrou-se eficiente como alternativa pedagógica que permitiu promover habilidades associadas ao processo de resolução de problemas relacionados com a prática do futuro professor.

Palavras-chave: Blended Online POPBL; FormaÇÃo de Professores; PBL; Projetos.

ABSTRACr This study aims to investigate the methodological approach of Project Organized and Problem Based Learning combining activities online and face to face (Blended Learning) to promote problem-solving skills in initial teacher training through digital information and communication technology (ICT). To meet this goal, we developed a qualitative study through a research-type intervention that analyzed the phenomena that occurred with the implementation of Blended Online POPBL approach as a pedagogical strategy in 
a discipline "Introduction to Computers" in the first year of a degree course in Chemistry. For the survey data were considered online interactions, self-assessments, reports, projects developed and questionnaires. Data analysis showed that the Blended Online POPBL approach proved to be effective as an educational alternative that allowed promote skills associated to problem-solving process related to the practice of the future teacher.

Keywords: Blended Online POPBL; Teacher Training; PBL; Projects.

RESUMen Este studio tiene como objetivo investigar el enfoque metodológico del Aprendizaje Basado en Problemas y Organizado en Proyectos que combina actividades online y presenciales (Blended Learning) para promover habilidades de resolución de problemas en la formación inicial de profesores a través de las Tecnologías Digitales de Información y Comunicación (TDIC). Para atender a ese objetivo, se desarrolló un estudio de carácter cualitativo, mediante una investigación del tipo intervención que analizó los fenómenos que ocurrieron con la implantación del enfoque Blended Online POPBL (Project Organized and Problem Based Learning) como estrategia pedagógica en una disciplina de "Introducción a la Computación" en el primer año de un curso de licenciatura en Química. Para el levantamiento de los datos fueron consideradas las interacciones online, autoevaluaciones, informes, Proyectos desarrollados y cuestionarios. El análisis de los datos evidenció que el enfoque Blended Online POPBL se mostró eficiente como una alternative pedagógica que permitió promover habilidades asociadas al proceso de resolución de problemas relacionados con la práctica del future profesor.

Palabras clave: Blended Online POPBL; Formación de Profesores; PBL; Proyectos.

\section{INTRODUÇÃO}

A abordagem Blended Online POPBL possui atributos que estão na vanguarda das pesquisas no campo educacional, uma vez que implica atividades realizadas por meio da metodologia ativa POPBL (Project Organized and Problem-Based Learning) em um ambiente que mistura as modalidades online e presencial (Blended Learning). A metodologia ativa POPBL é uma variante do clássico PBL (Problem-Based Learning) e pode ser traduzida como Aprendizagem Baseada em Problemas e Organizada em Projetos, nesse caso, a resolução de problemas resulta, necessariamente, no desenvolvimento de um projeto que confere um sentido de validade aos conteúdos de estudo (SOUSA, 2015). Essa abordagem do "aprender fazendo" está fundamentada nos estudos do filósofo pragmatista John Dewey. De acordo com Dewey (1952b), a educação começa com a curiosidade do estudante, dessa forma, a aprendizagem acontece por intermédio da experimentação ativa dos fenômenos sobre os quais o estudante deseja adquirir conhecimentos. É importante enfatizar que a produção intelectual de Dewey é considerada a matriz conceitual das metodologias ativas, por essa razão, este estudo está ancorado em seus textos, que, embora tenham sido produzidos no início do século XX, se mantêm extremamente atuais, o que denota o aspecto visionário do pensamento de Dewey.

Entre as razões que culminaram na investigação da abordagem Blended Online POPBL em uma disciplina de "Introdução à Computação" no curso de Licenciatura em Química, a 
mais significativa se refere ao fato de que muitas vezes não fica claro para os estudantes a importância da disciplina em um curso que, embora também seja da área de ciências exatas, não tem o objetivo de formar profissionais da Computação (SOUSA, 2015). A abordagem pedagógica que concebe as Tecnologias Digitais de Informação e Comunicação (TDIC) como elementos isolados do currículo faz que muitos estudantes não os legitimem como recursos que se apresentarão de modo transversal na sua prática profissional e, por esse motivo, não têm a clareza de como esses conteúdos podem auxiliar na resolução de problemas.

Posto que a disciplina de "Introdução à Computação" em um curso de Licenciatura em Química oferece uma situação propícia e desafiante para estudar uma intervenção, focando a metodologia ativa POPBL, faz-se necessário argumentar sobre a escolha da modalidade Blended Learning. De acordo com as Diretrizes Curriculares, a formação do licenciado em Química implica autoaperfeiçoamento contínuo, capacidade para estudos individuais ou em grupo, iniciativa na busca de soluções para questões individuais e coletivas relacionadas com o ensino de Química, bem como, habilidade para acompanhar as rápidas mudanças tecnológicas (BRASIL, 2001). Portanto, essas características, sobretudo a necessidade de acompanhar as transformações tecnológicas, fazem da disciplina de "Introdução à Computação" um campo fértil para o estudo da modalidade Blended Learning como ambiente para a metodologia POPBL (SOUSA, 2015).

Ainda para justificar a escolha da modalidade Blended Learning nesta pesquisa, soma-se o fato de o Ministério da Educação (MEC) ter publicado em 28 de dezembro de 2018 a Portaria $n^{\circ} .1 .428$ (BRASIL, 2018), que autoriza as Instituições de Ensino Superior incluírem em seus cursos disciplinas na modalidade a distância. Todavia, a portaria deixa claro que a oferta de disciplinas a distância não deve ultrapassar $20 \%$ da carga horária total do curso, ainda assim é uma importante conquista no sentido de o MEC legitimar e, de certa forma, estimular a educação a distância nos cursos presenciais. Nesse sentido, Horn e Staker (2015) apontam que as escolas estão chegando a um ponto crítico, em uma transformação digital que mudará para sempre a forma como as pessoas aprendem. Moran (2015) concebe essa transformação como algo positivo, uma vez que, segundo o autor, a modalidade blended será o modelo predominante de educação, especialmente na formação universitária. Contudo, Moran et al. $(2005$, p. 2) vêm preconizando há algum tempo que deve ficar sob responsabilidade de cada instituição a definição da porcentagem de disciplinas semipresenciais ou a distância e apontam que:

[...] o caminho da educação passa pela convergência entre o presencial e o virtual, na combinação integrada de tempos e espaços, tornando o currículo flexível. No Brasil temos o limite dos vinte por cento. Outros países estão implantando o ensino semi-presencial ou Blended Learning sem limites legais.

Entretanto, muitos projetos de cursos continuam privilegiando aspectos de uma educação reguladora, deixando de levar em conta as especificidades dos estudantes. Segundo Moran (2015, p. 28), as técnicas pedagógicas de muitos cursos presenciais ou a distância apresentam modelos poucos eficientes, uma vez que "Muitos cursos são previsíveis, com informação simplificada, conteúdo raso e poucas atividades estimulantes e em ambientes virtuais pobres, banais. Focam mais conteúdos mínimos do que metodologias ativas como de- 
safios, jogos, projetos". Nesses casos, a profusão de tecnologias disponíveis na educação que envolve atividade online é responsável por camuflar velhas teorias que continuam concebendo o estudante como mero espectador. Ainda que muitos cursos a distância ou semipresencial utilizem vastos recursos sonoros, visuais e de animações, eles carecem de metodologias de ensino e aprendizagem mais adequadas e epistemologicamente mais atualizadas com o contexto contemporâneo e com a própria matriz conceitual de tais modalidades.

Nesse âmbito, são frequentes os estudos que investigam as iniciativas que visam suprir a falta de conhecimento técnico por parte dos professores no que se refere ao uso das TDIC, seja na formação inicial ou continuada (PRETTO e PASSOS, 2017). Todavia, este artigo está alinhado com a perspectiva de Kurtz e Da Silva (2018), os quais indicam que é preciso focar perspectivas que desconstruam a concepção instrumentalista das TDIC, enfatizando a necessidade de um processo formativo que as contemple como ferramentas cognitivas que sirvam como parceiras intelectuais na resolução de problemas, indo além da formação tecnicista para conceber os professores como pessoas capazes de refletir criativa e criticamente sobre o mundo. Reforçando essa visão, Alonso e Silva (2018) realizaram uma revisão bibliográfica acerca das pesquisas em educação online e consideram que as tecnologias têm sido compreendidas, segundo uma visão tecnocêntrica, pontual e em perspectiva micro, apartadas das práticas sociais. De acordo com os autores, a tendência é incentivar a reflexão e recriação de teorias pedagógicas que concebam as TDIC em contextos menos instrumentais em favor de uma educação articulada com as complexas estruturas contemporâneas.

Se a abordagem pedagógica implica a concepção instrumentalista dos conteúdos, também tem impacto no que diz respeito ao crescente interesse em desenvolver a formação de professores para se adequar às habilidades requeridas no século XXI. Isso justifica a necessidade de abordagens nas quais os estudantes aprendam a enfrentar desafios que envolvam análise, argumentação, interpretação e permitam que resolvam problemas em contextos diferentes, mediante a aprendizagem colaborativa. Por meio desse processo, os estudantes negociam seus pontos de vista particulares, a fim de chegar a um entendimento compartilhado ou cognição do grupo em favor da resolução de problemas (HÄKKINEN, 2017).

Diante das problemáticas apresentadas, este estudo tem por objetivo investigar as implicações da abordagem Blended Online POPBL para promover habilidades processuais de resolução de problemas na formação inicial de professores por meio das TDIC, sobretudo no que se refere às etapas fundamentais da abordagem, a saber, a investigação, o trabalho em equipe e a resolução de problemas propriamente dita.

\section{BLENDED ONLINE POPBL}

As metodologias ativas problematizadoras foram concebidas inicialmente para a modalidade presencial. Contudo, como as TDIC vêm evoluindo em ritmo acelerado, muitas iniciativas têm sido realizadas para combinar metodologias ativas problematizadoras com a aprendizagem colaborativa apoiada por computador, sobretudo porque com frequência a Aprendizagem Baseada em Problemas ocorre no contexto de pequenos grupos. Atualmente, a alta disponibilidade da internet torna possível implementar metodologias ativas problematizadoras em ambientes híbridos (Blended Learning) que combinam atividades 
online e presencial com o intuito de apoiar e proporcionar uma interação significativa entre estudantes, professores e recursos para aprendizagem (AL-DOUS; SAMAKA, 2015).

Focando as ferramentas assíncronas de comunicação presentes nos AVA (Ambiente Virtual de Aprendizagem), Jonassen (2000), referência nos estudos do uso da tecnologia como ferramenta cognitiva, chama a atenção para o modelo Computer-Supported Collaborative Argumentation (CSCA), ou em sua tradução literal, Argumentação Colaborativa Apoiada por Computador. O modelo CSCA prevê uma organização hierárquica para estruturar as comunicações e apoiar a comunicação com foco na resolução de problemas.

O problema no processo do modelo CSCA corresponde a uma afirmação incompleta ou um dilema. A partir do problema é definida uma proposta de solução. As propostas, ou planos de ação, são dirigidas por afirmações encontradas no problema. Desse modo, o argumento é elaborado a partir de evidências que apoiam uma proposta. Assim, para resolverem um problema, "os estudantes submetem propostas com argumentos sustentáveis" (JONASSEN, 2000, p. 280). A efetividade da argumentação acontece entre os estudantes que se dedicam a propor, criticar, construir argumentos e explicações, refletindo e avaliando as ideias uns dos outros em ambientes compartilhados (CHEN e LOOI, 2017).

Da mesma maneira, o modelo Open Learning Environments (OLE), cuja tradução é Ambientes de Aprendizagem Aberta, proposto por Michael Hannafin, Susan Land e Kevin Oliver (2012), é centrado no estudante e promove a construção do conhecimento baseado na resolução de problemas, focando o desenvolvimento do pensamento crítico e múltiplas perspectivas para resolução de problemas. O modelo OLE prevê um ambiente virtual ancorado na teoria da aprendizagem aberta que valoriza o contexto e a experiência. Os pressupostos teóricos sobre a pedagogia que fundamenta o modelo OLE refletem contextos autênticos de aprendizagem fundamentada em problemas ou em projeto que mobilizam esforços individuais para aprender (LAND e OLIVER, 2012). Tal ambiente conduz os estudantes em experiências que promovem a compreensão por meio de exploração, oferecendo oportunidades para conhecer uma ideia ao invés de simplesmente falar a respeito dela. A estruturação do modelo OLE possui algumas diretrizes metodológicas, como podemos ver no Quadro 1 (LIMA; CAPIT ̃̃O, 2003).

\section{Quadro 1: Métodos do modelo OLE de Hannafin, Land e Oliver.}

\begin{tabular}{|c|c|c|c|}
\hline Estabelecer o Contexto & $\begin{array}{l}\text { Recursos de } \\
\text { Informação }\end{array}$ & Ferramentas Cognitivas & Suporte \\
\hline $\begin{array}{l}\text { - Externamente } \\
\text { imposto } \\
\text { - } \begin{array}{l}\text { Externamente } \\
\text { Induzido }\end{array} \\
\text { - Definido pelo } \\
\text { estudante }\end{array}$ & $\begin{array}{ll}\text { - } & \text { Eletrônicos } \\
\text { - } & \text { Impressos } \\
\text { - } & \text { Humanos }\end{array}$ & $\begin{array}{l}\text { - } \begin{array}{l}\text { Processamento } \\
\text { de informação }\end{array} \\
\text { - } \begin{array}{l}\text { Manipulação da } \\
\text { informação }\end{array} \\
\text { - } \begin{array}{l}\text { Ferramentas de } \\
\text { comunicação }\end{array}\end{array}$ & $\begin{array}{ll}\text { - } & \text { Conceitual } \\
\text { - } & \text { Metacognitivo } \\
\text { - } & \text { Processual } \\
\text { - } & \text { Estratégico }\end{array}$ \\
\hline
\end{tabular}

Fonte: Adaptado de Lima e Capitão (2003, p. 98). 
A respeito de como estabelecer o contexto no Modelo OLE, Lima e Capitão (2003) consideram que pode ser definido da seguinte maneira:

Externamente imposto: o contexto é apresentado ao estudante de forma fechada e com necessidades especificas;

Externamente induzido: o contexto é apresentado de forma aberta, cabe ao estudante determinar quais as necessidades específicas, o contexto é uma situação-problema real que o estudante interpreta e especifica as necessidades que irá tratar;

Definido pelo estudante: $\mathrm{O}$ estudante determina o contexto e o problema que irá tratar.

No tocante aos recursos de informação, estes podem ser eletrônicos (aplicativos, vídeos, animações digitais, jogos), impressos (livros, revistas, jornais) ou humanos (especialista, professores, profissionais).

De acordo com Salomon et al. (1992), entendem-se por ferramentas cognitivas os recursos tecnológicos que realizam uma operação cognitiva pelo estudante e assim podem ser considerados como parceiros no processo que Pea (1989 apud Salomon et al., 1992) chama de "cognição distribuída". As ferramentas cognitivas permitem que os estudantes manipulem as fontes de informação e suas ideias, seu uso varia de acordo com o contexto em que se apresenta o problema. Genericamente, as ferramentas cognitivas podem ser de processamento da informação (motores de busca na web, processadores de texto), manipulação da informação (planilhas eletrônicas, linguagens de programação) e ferramentas de comunicação (assíncrona ou síncrona).

O suporte ao estudante funciona como mecanismos de apoio destinados a amparar os esforços do estudante para entender. O suporte é normalmente concebido para fornecer as seguintes funções: Orientação conceitual (auxilia o estudante nos conceitos que são importantes considerar, é aplicada quando se define o contexto do problema); Orientação metacognitiva (incita o estudante a pensar sobre o próprio pensamento usado para resolver o problema, a reflexão, nesse caso, leva a um patamar de ideias mais elevado); Orientação processual (guia o estudante para conhecer os recursos do ambiente virtual de aprendizagem); Orientação estratégica (oferece auxílio ao estudante nas decisões que ele deve tomar para resolver o problema) (LAND e OLIVER, 2012).

Tais modelos exibidos permitem reconhecer uma gama de similaridades com a abordagem Blended Online POPBL, no entanto, convém ressaltar que sua proposição, seja utilizando características do modelo CSCA ou do modelo OLE, não significa a substituição do modelo pedagógico convencional, mas é uma abordagem dedicada a complementar e desenvolver o que já existe (SAVIN-BADEN, 2006). Dessa maneira, os estudantes que tradicionalmente tomam notas a partir de comentários dos professores e respondem a questões elaboradas por estes veem-se no POPBL a fazer perguntas e a responder aos seus próprios pares, seja presencialmente em sala de aula ou em momentos online (DELISLE, 2000).

Se o papel fundamental do professor no Blended Online POPBL é estimular o pensamento crítico e o autoaprendizado e propor situações para a promoção da aprendizagem colaborativa, o papel do estudante é, efetivamente, pensar e não só replicar ou memorizar informações. Nessa perspectiva, Dewey (1959a, p. 104-105) argumenta que tal habilidade deve ser desenvolvida em um contexto propício, pois "provavelmente, a causa mais frequente pela qual a escola não consegue garantir que os estudantes pensem verdadeiramente 
é que não se provê uma situação experimentada, de tal natureza que obrigue a pensar, exatamente como o fazem as situações extra-curriculares".

É imperativo salientar que um contexto com situações verdadeiramente experimentadas pelos estudantes está intimamente relacionado com a qualidade das situações problemáticas que serão apresentadas a eles. Tal tema será abordado na próxima seção.

\section{A QuALIDAde dos PROBLemas nO PROCESSO EDUCATIVO}

Para o psicólogo norte-americano Jerome Bruner (1969), um problema deriva de uma situação incerta que se forma na estrutura cognitiva de um indivíduo. Embora incerta, a situação se relaciona com os seus hábitos, levando-o a uma inquietação, um desequilíbrio que o induz a elaborar ideias e realizar ações, a fim de minimizá-la ou aplacá-la. Dessa forma, os problemas genuínos desencadeiam nos estudantes motivação para estudar e, por conseguinte, contextualizam o conhecimento do conteúdo (HUNG, 2016).

Os problemas escolares presentes em livros didáticos estão mais próximos de tarefas a serem cumpridas do que de problemas a serem solucionados. Nesse contexto, um problema para um adolescente se refere à estratégia que irá definir para derrotar o inimigo em um jogo de videogame. Esse jovem se mobiliza, conversa com amigos, investiga no Youtube, busca meios para resolver o problema e eliminar o desequilíbrio em que se encontra. Por que, então, esse mesmo adolescente não legitima como um problema o conteúdo escolar que trata das estratégias políticas dos norte-americanos ou russos durante a guerra fria? Não há, nessa situação, uma incorporação do problema, algo dentro desse adolescente diz: "Esse problema não é meu". Logo, não há interesse em buscar uma solução, há apenas o interesse em satisfazer as exigências propostas pelo professor. Sobre as convenções e modelos que regem os problemas no sistema escolar Dewey (1959b, p. 171) argumenta:

\footnotetext{
Devido à ausência de materiais e ocupações que gerem problemas reais, os problemas do estudante não são seus; ou antes, são seus unicamente em sua qualidade de estudantes, mas não em sua qualidade de seres humanos. Daí uma lamentável decepção quando se procura aplicar fora do âmbito da escola os conhecimentos adquiridos por essa forma.
}

Nos anos noventa, Juan Ignácio Pozo (1998), organizou uma publicação que é considerada referência quando se busca identificar a qualidade dos problemas envolvidos na aprendizagem e estabelecer as diferenças entre os que são simulados e os reais empregados na sala de aula. O que distingue um verdadeiro problema de uma tarefa ou exercício é o contexto da resolução e o modo como o estudante o concebe. Em um exercício ou tarefa, dispomos de mecanismos que nos levam à solução de forma imediata, uma vez que esses mecanismos são padronizados e aplicados sem que haja uma consciência da ação. Já em um problema verdadeiro, não dispomos de procedimentos automáticos que nos permitam solucioná-los. Afinal, ele exige um processo de reflexão ou uma tomada de decisão dos passos a serem seguidos (POZO, 1998).

Para Csapó e Funke (2017), a resolução de problemas é claramente uma das habilidades consideradas essenciais para a sociedade do século XXI, uma vez que, no cotidiano, as 
pessoas necessitam de conhecimentos procedimentais que complementem os conceituais. Em uma atividade de solução de problemas, os estudantes se deparam com uma situação que se comporta de maneira semelhante à realidade. Nesse caso, o processo de solução de problemas normalmente ocorre em duas fases principais: uma se refere à aquisição e a outra à aplicação de conhecimento. Os solucionadores de problemas precisam mobilizar um número de habilidades de raciocínio operacional, bem como, habilidades de pensamento de ordem superior em ambas as fases.

É importante salientar que essa perspectiva não é nova. Na obra Democracia e Educação, de 1916, Dewey faz apontamentos nesse sentido e argumenta que as tarefas têm apenas o objetivo de instruir sobre algum ponto do programa escolar, a experiência do estudante não é relevante, é um problema do professor ou do compêndio, formulado unicamente para fins de aprovação do estudante. Um problema real, por sua vez, apresenta-se naturalmente em alguma situação da experiência pessoal do estudante, desperta sua observação e provoca a experimentação fora da escola, porque é legitimado pelo estudante (DEWEY, 1959b).

Os estudantes conseguem compreender e recordar um conteúdo quando observam relações da matéria estudada com as suas próprias vivências, ou seja, o problema deve ser responsável por colocar a aprendizagem no contexto da vida real (DELISLE, 2000). Nessa direção, o problema funciona como ponto de partida para a construção do conhecimento, quer dizer, ele representa um acontecimento ou conjunto de acontecimentos preparados por professores especialistas na matéria (FONT, 2004). Optar pela metodologia POPBL permite ao professor considerar qualquer situação, dentro ou fora da escola, como fonte de inspiração para o desenvolvimento de problemas que tenham relação com a vivência dos estudantes (DELISLE, 2000).

É conveniente ressaltar que as metodologias ativas apoiadas em problemas ou projetos têm sido altamente elogiadas, mas ao mesmo tempo muito criticadas. Nesse sentido, Silby (2013) argumenta que faltam evidências que apoiam a eficácia das metodologias problematizadoras, uma vez que o indicador que atesta a aprendizagem é ancorado principalmente em tentativa e erro. A abordagem de tentativa e erro tende a envolver a aquisição de habilidades ou conhecimento processual, ou seja, habilidades no processo de resolução de problemas. Contudo, Silby (2013) considera que a educação envolve mais do que conhecimento processual, envolve também o conhecimento proposicional. O autor é bastante enfático ao considerar que o problema das abordagens que envolvem pouca instrução direta é que, muitas vezes, os estudantes se arriscam na aquisição de conhecimentos equivocados e o raciocínio é ineficaz. Nessa mesma direção, Forrester (2004) aponta para uma espécie de relativismo que pode impactar negativamente na educação do futuro, sendo que a capacidade de resolver um problema pode ser limitada pelo acesso do estudante à informação.

Dessa maneira, podemos observar que há uma tensão entre a aprendizagem aberta proporcionada pelo PBL/POPBL e a aprendizagem determinística do currículo formal. Opositores dessas metodologias ativas se preocupam com possíveis lacunas no conhecimento dos estudantes, contudo ignoram que lacunas similares também acontecem no modelo tradicional. Além disso, o mundo real está cheio de problemas, projetos e desafios, no qual a proposição de um ambiente que reflita essa realidade faz todo sentido (STROBEL e VAN BARNEVELD, 2015). 


\section{Metodologia}

A estrutura metodológica deste estudo é predominantemente qualitativa, todavia há alguns indicadores quantitativos para subsidiar as inferências no tocante aos resultados atingidos e, desse modo, conferir maior rigor às análises realizadas (SOUZA e KERBAUY, 2017). A etapa empírica desta pesquisa se trata de uma intervenção que consistiu no emprego da abordagem educacional Blended Online POPBL como metodologia pedagógica em um grupo com 44 estudantes de uma disciplina de "Introdução à Computação" ofertada no primeiro ano de um curso de Licenciatura em Química de uma Universidade Estadual.

Antes de descrever como ocorreu a intervenção, é de extrema relevância destacar que as situações-problema, ou cenários, utilizadas foram organizadas em torno de projetos que contemplassem em seu desenvolvimento os conteúdos programáticos da disciplina de "Introdução à Computação" e também o contexto dos estudantes. Nesse caso, o modelo de PBL que foi referência para essa intervenção tem inspiração no modelo POPBL da Universidade de Aalborg, na Dinamarca (MOESBY, 2009). Para viabilizar a intervenção, o pesquisador, professor responsável pela implantação do Blended Online POPBL na disciplina, formulou três situações-problemas contemplando em sua resolução a aprendizagem de conteúdos fundamentais para a criação de um projeto. O professor optou por formular previamente apenas a primeira situação-problema para ser o ponto de partida da abordagem Blended Online POPBL. As outras situações-problemas foram desenvolvidas ao longo da disciplina, baseando os problemas em um contexto familiar aos estudantes. Dessa forma, a partir da segunda situação-problema, os problemas faziam referência ao contexto social, econômico e cultural dos estudantes, bem como, às situações práticas do cotidiano da área do curso e foram organizados de modo a contemplar pequenas unidades temáticas do conteúdo programático da disciplina (HUNG, 2016).

A estrutura textual dos problemas foi organizada da seguinte forma: título do problema, tema, objetivos de aprendizagem, cronograma de desenvolvimento, problema, produto a ser desenvolvido, modo de avaliação e recursos para a aprendizagem (bibliografia). A organização textual dos problemas está em concordância com o que, segundo Caprara (2001, p. 146), deve conter no texto de um problema semiestruturado:

1) um título, potencialmente sugestivo, que direcione o interesse para um tema central; 2) um texto claro, não muito extenso nem prolixo; 3) instruções colocadas ao final do texto e às vezes expressadas de forma interrogativa e que, assim como o título, dirijam a discussão para um tema definido e explicitem como abordar o problema.

Com relação à proposta das situações-problema, a forma como foram redigidas faz que sejam identificadas como "obstáculo de processo" ou "cenários", pois foram construídas ao redor de um personagem (o próprio estudante já como profissional da sua área) que precisa realizar uma ação e não sabe como proceder (CAPRARA, 2001; RIBEIRO, 2008). Esse tipo de situação coloca o estudante em uma posição de aprendiz de profissional, o que significa lhe dar alguma coisa para fazer e não alguma coisa para estudar. 
No primeiro encontro presencial, o professor apresentou o plano de curso aos estudantes, discursando sobre a modalidade Blended Learning e acerca da metodologia POPBL. Após esclarecer algumas dúvidas, o professor solicitou aos estudantes a formação de grupos com cinco a oito estudantes, que receberam a primeira situação-problema para resolvê-la de forma colaborativa. A situação-problema foi exibida aos grupos sem informações anteriores para a sua elucidação, funcionando como ponto de partida e condutora do processo de aprendizagem. A solução de alguns problemas se desenvolveu em caráter interdisciplinar, integrando informações de outras disciplinas presentes no curso (MASETTO, 2004).

Para o levantamento dos dados, foram utilizadas duas técnicas: aplicação de questionário e coleta de documentos. O objetivo do questionário foi levantar dados acerca das concepções dos estudantes sobre a abordagem Blended Online POPBL, além de fazer que registrassem suas reflexões a respeito de seus desempenhos acadêmicos nessa modalidade. O questionário foi composto por questões abertas, que permitiam respostas livres e também por questões fechadas que traziam alternativas para serem escolhidas. Na coleta de documentos, foram considerados os quadros referenciais de cada grupo, os relatórios individuais, os questionários de autoavaliação do processo de resolução de problemas, os projetos desenvolvidos e 945 mensagens publicadas em 27 fóruns do AVA. Para trabalhar com essa grande quantidade de dados, foi necessário imprimir e ler cada um dos documentos para determinar quais possuíam conteúdos relevantes para a pesquisa.

Os dados coletados foram analisados por meio da técnica da Análise de Conteúdo, buscando a inferência de conhecimentos referentes à produção ou recepção das mensagens produzidas pelos participantes (BARDIN, 2009). Convém entender por mensagens qualquer artefato de comunicação, seja ele manifestado na forma oral ou escrita e devidamente registrado. Contudo, essa técnica de análise foi complementada com dados quantitativos a fim de assegurar o rigor metodológico nas inferências. Os dados quantitativos foram tabulados por meio do software PSPP, ${ }^{1}$ que permitiu obter informações mediante cruzamentos entre questões, além disso, o software MS-Excel foi utilizado para a criação dos gráficos. Dessa maneira, para atender ao objetivo desta pesquisa, foram definidas três unidades para análise e discussão que se referem às etapas de resolução de problemas: 1) Processo de Investigação; 2) Trabalho em equipe; 3) Resolução de Problemas.

\section{ReSUlTAdOS E DiscuSSõeS}

Convém salientar que, nesta seção, todas as manifestações verbais (escritas ou faladas) dos participantes serão transcritas entre aspas e em itálico. Essa notação indica que se trata da transcrição literal das expressões verbais dos participantes. A transcrição dos diálogos será apresentada precedida pelo uso do travessão (-). Além disso, a identidade dos participantes será preservada, eles serão identificados por um codinome formado pela letra "A" e um número no intervalo de 1 a 44 .

O software gratuito PSPP (GNU - General Public License) permite análises estatísticas sobre matrizes de dados. Site oficial do PSPP: www.gnu.org/software/pspp. 


\section{Processo de Investigação}

A metodologia POPBL pode ser considerada, com outras metodologias ativas, uma metodologia também fundamentada na investigação, ou seja, a Aprendizagem Baseada em Inquérito é a estrutura principal do PBL/POPBL, no que se refere ao aspecto científico da investigação (OGUZ-UNVER; ARABACIOGLU, 2011; VALENTE, 2014). A partir dessa premissa, consideraremos nesta análise a relevância do processo investigativo que os estudantes empenharam. Para tanto, é importante enfatizar que o processo de investigação encontra estímulo a partir de uma situação geradora de dúvidas.

Para Peirce (1975), representante do pragmatismo como Dewey, a dúvida é um estado desagradável e incômodo, lutamos para nos libertar da dúvida e passar a um estado de crença mais confortável. Quando um estado de crença já está instituído, parece haver pouca disposição em se abrir para um estado de dúvida. A crença leva o homem a se comportar de determinada maneira em alguma ocasião, já a dúvida conduz a um esforço para atingir um estado de crença ou de nova crença sobre algo. Peirce (1975) chama esse esforço de investigação ou inquirição. Dessa maneira, quando nos dispomos a inquirir acerca de algo, fazemos isso em razão de um estado de dúvida e não de crença. O diálogo registrado no fórum ilustra o estado de crença, seguido pela dúvida até culminar no processo de investigação:

- "então, depois de escolhermos os alimentos, o próximo passo é colocá-los na planilha, vcs sabem como fazer para sair o $\mathrm{pH}$ de acordo com a cor indicada com o experimento" (A05).

- "Euи acho que seei *_* HAHA tem uma opção em fórmulas que vc preenche com a condição, a opção se não me engano é a opção "SE". Dai vai aparecer o lugar das condições: $S E>7$ básico, $S E<7$ ácido, e $S E=7$ Neutro" (A06).

Em um primeiro momento a estudante A06 manifestou sua crença, sem demonstrar necessidade de investigar algo que para ela já era tido como certo. Seis minutos após revelar sua crença, a estudante A06 refletiu e completou:

— "Maaaas na dúvida eu vou olhar na apostila do material de apoio" (A06).

E dezenove minutos após ler a apostila, a estudante A06 replica em estado de dúvida:

— "Muiiito mais complicado do que eu pensei, kkkkkkk" (A06).

A fala da estudante A06 denota que a incerteza ou dúvida desempenha um importante papel na investigação, ideia compartilhada por Dewey (1950, p. 123), para quem a investigação emerge da incerteza para a integração e o controle: "A investigação é a transformação controlada ou direcionada de uma situação indeterminada para outra que é tão determinada em suas distinções e relações constituintes que converte os elementos da situação original em um todo unificado".

Já discorrido sobre a importância da dúvida para o processo de investigação, abordaremos agora a contribuição do Blended Online POPBL para a aquisição, por parte dos estudantes, de habilidades referentes aos recursos de investigação e às fontes de informação fornecidas por tais recursos. É conveniente, porém, esclarecer sobre o modo como os recur- 
sos de investigação e as fontes de informação serão abordados nesta análise. Um recurso de investigação se refere ao meio pelo qual um indivíduo obtém a informação, seja esse meio um livro, a internet, a televisão ou outra pessoa. Já a fonte de informação diz respeito às várias formas que uma informação pode assumir em um meio.

A análise sugere que grande parte dos estudantes tende a utilizar um único meio de investigação, porém, a natureza incerta dos problemas no POPBL levou os estudantes a aprofundarem as possibilidades oferecidas por esse meio. As seguintes falas da autoavaliação ilustram esta percepção: "Utilizei vários sites para construir o manual e a vídeo-aula" (A21) e "fundamental foi a internet, pois utilizei vários link's para formar uma ideia consistente" (A10).

Como podemos observar nas falas anteriores, ao falarem sobre o uso da internet como recurso de investigação, os estudantes, com frequência, associavam tal recurso ao termo "vários". Embora a internet tenha sido um recurso investigativo amplamente utilizado, os estudantes necessitaram legitimar tal recurso como um meio confiável para obter informações, assim, o uso do termo "vários" pelos estudantes implica que o recurso foi empregado considerando suas muitas possibilidades. Por sua vez, para os estudantes, o livro é um recurso de investigação historicamente legitimado e eles consideram que deveriam ter utilizado mais tal recurso, como constatam as autoavaliações: "Poderia ter pesquisado mais em livros, biblioteca" (A29). Além disso, na visão dos estudantes, os recursos de investigação devem proporcionar fontes de informação relevantes e confiáveis: "Utilizei o problema 1 dado pelo professor para adquirir conhecimento ao ir atrás de fontes consistentes para utilizar na resolução do problema" (A20).

Observando o processo de investigação, por uma visão mais objetiva, podemos inferir que, embora a autoavaliação realizada pelos estudantes demonstre que eles aumentavam a gama de recursos investigativos à medida que resolviam os problemas (Gráfico 1), as falas sugerem que não havia tanta alternância entre esses recursos.

\section{Gráfico 1: Autoavaliação referente ao uso de vários recursos na investigação.}

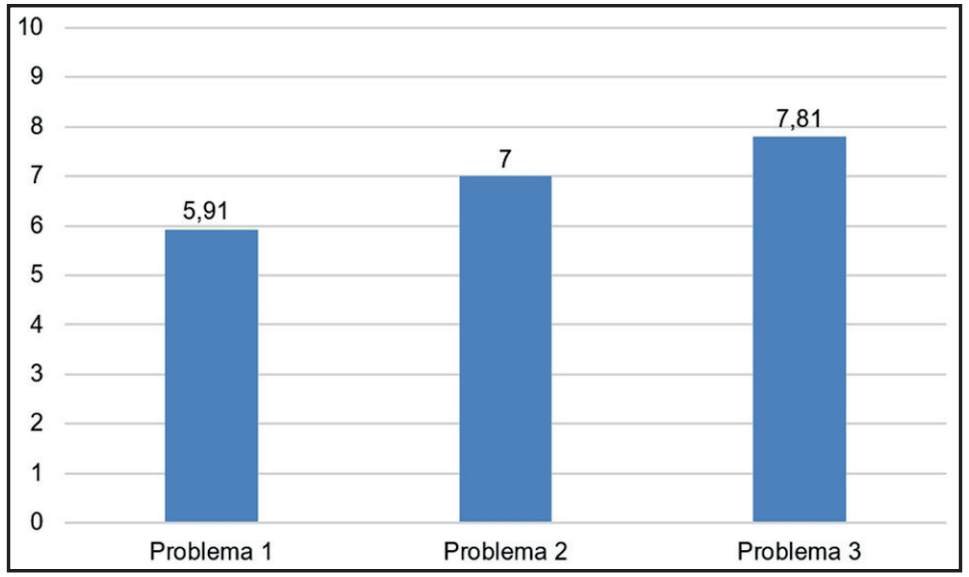

Fonte: Elaborado pelo Autor. 
Ao relatarem sobre os meios de pesquisa, havia na "voz" dos estudantes uma predominância, bastante significativa, da internet como recurso escolhido para investigação. Também, em observações realizadas durante as aulas presenciais, notou-se que os estudantes demonstraram uma valorização da internet em detrimento de qualquer recurso de investigação. Seguem as manifestações dos estudantes nas autoavaliações sobre os recursos de investigações:

"-Utilizei somente internet" (A36).

“- Minha 'investigação' para compor o trabalho foi quase inteiramente pela inter$n e t "$ (A34).

"- Sites me auxiliaram e uma leitura rápida em um dos livros indicados pelo professor." (A13).

“-Utilizei um livro para aprender mais sobre PH, mas fundamental foi a internet" (A29).

De acordo com o Gráfico 2, podemos notar que a maioria dos estudantes optou por realizar suas pesquisas na internet, ainda que os profissionais da área e os livros também tenham tido relevância como meios de investigação.

\section{Gráfico 2: Recursos para pesquisa mais destacados pelos estudantes.}

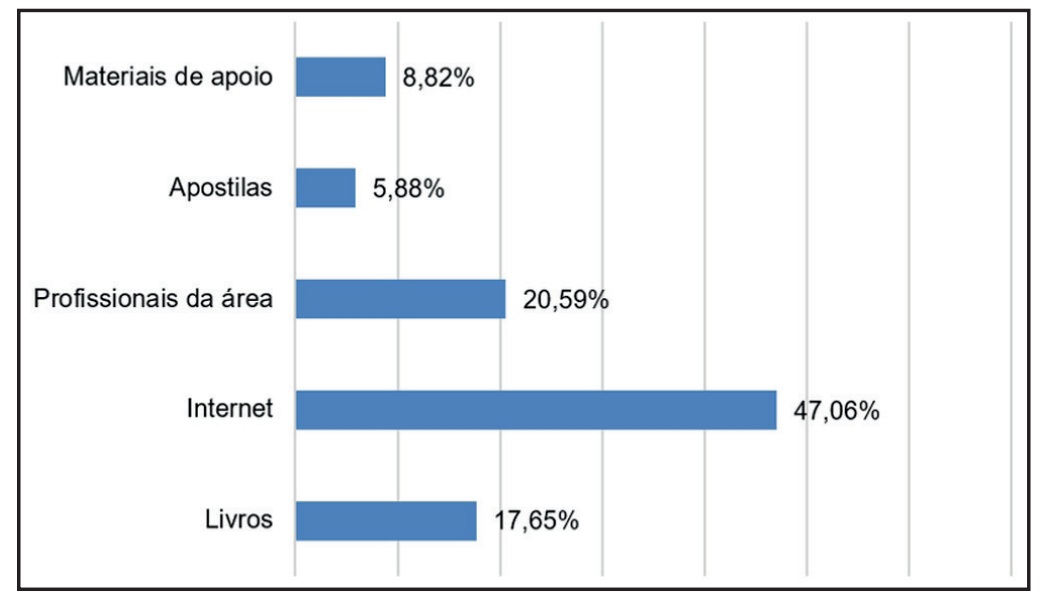

Fonte: Elaborado pelo Autor.

É importante frisar que não é intenção aqui definir se este ou aquele meio de investigação é mais confiável ou mais legítimo como fonte de informação. A intenção é demonstrar a dificuldade de se apelar para um meio de pesquisa, quando outro já está tão arraigado aos costumes acadêmicos dos estudantes. Embora o ideal fosse uma distribuição mais harmônica entre os recursos de pesquisa, ainda assim, mesmo que de forma tímida, a consulta aos profissionais da área teve sua representatividade entre os estudantes, as falas do fórum atestam essa observação: 
"_ Como havia dito, conversei com uma professora conhecida minha especialista no assunto. Estava tentando trazê-la para compartilhar suas experiências sobre o assunto, contudo, não foi possível, pois ela teve que viajar, problemas pessoais" (A19).

"- Vamos nos reunir e marcar com algum estudante da computação pra tirarmos nossas dúvidas e entendermos melhor como funciona e aprendermos como desenvolver" (A02).

Convém salientar que, por meio das respostas ao questionário, observamos que os estudantes consideram que a abordagem Blended Online POPBL foi responsável por potencializar suas habilidades investigativas, já que possibilitou um "Aprimoramento da questão de procurar informações sozinho" (A10) e "melhorei meu mecanismo de pesquisa" (A04), ou seja, a investigação é autorregulada pelo estudante. Nessa perspectiva, Bruner (1969, p. 20) considera que a habilidade de investigação deve ser trabalhada em sistemas educacionais que permitam a "aptidão progressiva de ir além da informação encontrada em uma única ocasião".

Assim, no que se refere à habilidade em selecionar recursos de investigação, esta pesquisa demonstrou que a internet tem uma relevância maior para os estudantes se comparada aos outros meios de investigação, o que parece bastante natural, considerando o componente online da modalidade Blended Learning e o fato de os estudantes pertencerem à geração conectada. Porém, no que tange à habilidade de selecionar as fontes de informação, essa intervenção possibilitou aos estudantes, em função do caráter incerto dos problemas apresentados, uma busca progressiva pela validação da informação mediante o julgamento de várias fontes.

\section{Trabalho em Equipe}

Esta seção intenciona abordar a contribuição da abordagem Blended Online POPBL em proporcionar aos estudantes um ambiente democrático, favorável para desenvolverem ou aprimorarem suas habilidades de trabalho em equipe. Para tanto, é importante definir o tipo de ambiente ou sistema democrático a que esta análise se refere. Para Palle Qvist (2006, p. 12), professor da Universidade de Aalborg, na Dinamarca, um ambiente democrático de aprendizagem:

É um sistema onde as decisões, processos e comportamentos relacionados à aprendizagem são estabelecidos por meio da argumentação (debate) ou negociação (diálogo), na votação ou consenso entre os afetados pela decisão, fazendo com que alcancem simultaneamente os resultados da aprendizagem, o conhecimento técnico e profissional e uma visão ampla (insight).

A partir das observações das interações ocorridas entre os integrantes dos grupos nos fóruns, notou-se que o ambiente virtual é responsável por desenvolver uma comunidade de sala de aula mais democrática, como atestam as seguintes falas registradas nas autoavaliações: “O grupo se dedicou, todo mundo ajudou, me enviando link's, fontes, que utilizei para formular minhas idéias e tanto para retirar exemplos quanto para melhor compreensão do assunto. Participei inteiramente com o grupo." (A11) e "O grupo se dedicou muito, então 
com ajuda de cada um montamos nossa resolução" (A05). Com base nas observações feitas pelos estudantes, é possível inferir que havia no grupo uma tentativa de compreender o problema sob diferentes perspectivas. Ainda sobre a habilidade de trabalhar em equipe de forma democrática, a estudante $\mathrm{A} 3$ reflete: "Acredito que todos contribuirram igualmente e a minha parcela não foi a menor". Na resolução da terceira situação-problema o estudante A26 observa no fórum: "Ae pessoal, o grupo tá bem mais unido hein. isso ae, pessoal". Essa fala confirma que a participação nas discussões do grupo no fórum é um potente desestimulador do frequente individualismo de nossa sociedade e seus sistemas educativos contemporâneos que privilegiam o isolamento social (SOUSA; SCHLÜNZEN JUNIOR, 2012).

No entanto, se manifestou entre os estudantes a consciência de que o fórum é um recurso que permite, inclusive, visualizar e acompanhar a falta de interações entre os estudantes nos grupos de trabalho. O relatório de uma estudante confirma essa visão: "o meu grupo não demonstrou interesse e preocupação com o trabalho, a maior parte fiz sozinha. Acho que deu para perceber isso pelo TelEduc" (A39).

Em geral, as falas dos estudantes demonstram que eles aprenderam a modificar seu estilo de trabalho ou pontos de vista para se adequarem a um sistema educacional que privilegiava a democracia. Por ocasião da resolução do segundo problema que abordava o uso do Excel para auxiliar em experiências químicas, o seguinte diálogo se destacou no fórum:

- "ok, eu vô procurar saber sobre esse experimento do suco de repolho roxo, parece bem legal, mas a minha dúvida é se precisaremos fazer isso realmente ou pegar dados da internet. I" (A06).

- "fazer o experimento mesmo na prática? acho que não, hein, dá uma pesquisada e tal. Achei um video sobre o experimento no youtube, dá uma olhada: http://www.youtube. com $/$ watch? $v=2 \mathrm{ObCzIVnLio.I"} \mathrm{(A38).}$

- "é foi o que eu vi depois, e concordo com vc, é melhor pegar resultados da internet e tabelar em ordem crescente ou decrescente de Ph. Essas coisas, agora vô ver o vídeo" (A06).

O diálogo sugere que as discussões do POPBL ampliadas em um AVA estimulam uma forma mais democrática de pensar, bem como, maior tolerância e respeito com relação às opiniões diferentes. Para alguns estudantes, as atividades de colaboração no grupo, em especial o brainstorm (chuva de ideias), foram decisivas para a resolução do problema: "Devido ao brainstorm diversas ideias foram dadas e desenvolvidas", escreveu A05 em seu relatório. Uma vez que o fórum permite o registro das discussões, potencializa o sentido de um ambiente educacional democrático, pois possibilita aos estudantes conhecerem e usarem suas habilidades de argumentação (debate) e negociação (diálogo), visando atingir um objetivo comum. Essa concepção também é partilhada por outro estudante na autoavaliação: "Durante os debates apresentei algumas ideias relevantes e ajudei a aprimorar algumas existentes" (A13).

Os estudantes nos grupos POPBL continuamente se comprometiam com a discussão, persuasão e consenso em uma diversidade de participação que fornecia elementos de interação mais democrática e robusta. No diálogo a seguir, duas estudantes discutem no fórum 
sobre a resolução do terceiro problema, que consistia em elaborar um programa de computador que auxiliaria os estudantes do ensino médio em cálculos químicos:

— "Eu até pensei em colocar derivada e integral na calculadora, mas nós devemos considerar que os estudantes são do colegial [Ensino Médio], então, que tal além de molaridade e concentração, um pouco de equação dos gases?" (A07).

- "Concordo, tem que ver certinho se o conteúdo bate com o do colegial, Lei dos Gases seria interessante mesmo e esses cálculos que caracterizam as soluções também... e Estequiomoetria, que é uma matéria de muita dificuldade da maioria no colegial" (A06).

A respeito do empenho dos estudantes em fazer que diferentes percepções sobre a resolução de um problema convergissem, eles refletem em seus relatórios: "cada membro do grupo formulou sua própria calculadora e depois todas foram unidas em uma só" (A41), "Foram dadas diversas ideias sobre a resolução do problema" (A10). As falas demonstram que, como na vida, esses estudantes são pessoas que confrontam com outras pessoas com ideias e informações díspares. Dessa maneira, quando o estudante A16 pondera: "Executei minha parte com empenho, só não sei se foi o suficiente para que ficasse bom" ele está falando do esforço para reconciliar suas limitações com seus pares para se converterem em um grupo harmônico.

Porém, algumas pessoas não foram hábeis em reconciliar as diferenças no grupo, sobretudo, as de atitudes. A fala do estudante A15 em seu relatório ilustra essa inferência: "Não auxiliei muito na parte de produção do material, fiquei um pouco afastado, pois alguns membros se isolaram neste sentido, não dando abertura. No próximo problema irei conversar este assunto com o grupo". Outros grupos foram mais hábeis ao distribuir as responsabilidades entre seus membros e deixar claro as regras para colaboração como esclarece a seguinte fala coletada na autoavaliação: "Todo o grupo participou de pelo menos uma etapa de desenvolvimento do trabalho" (A12).

As evidências empíricas desta pesquisa não são abrangentes o suficiente para determinar se as habilidades referentes ao trabalho em equipe demonstradas pelos estudantes perdurarão com o tempo, para isso seria necessário um estudo longitudinal que os acompanhasse após a intervenção. Porém, é possível concluir, mediante observações e falas dos estudantes, que os recursos de comunicação de um AVA para apoiar os processos do POPBL possuem elementos para que habilidades de trabalho em equipe sejam exercitadas e estimuladas.

\section{Resolução de Problemas}

Uma vez que nos propomos a analisar as habilidades relacionadas à resolução de problemas, é preciso, em um primeiro momento, definirmos a natureza de tais problemas. Quando falamos sobre o uso de situações-problema na educação, estamos falando também de uma gama de problemas implícitos a essa situação, ou seja, não representa um único problema, mas um mais geral com outros mais específicos. Uma situação se configura como um problema para o estudante, quando há um desequilíbrio entre seus conhecimentos e a situação que se apresenta. Paralelo a isso, a manifestação da vontade em resolver o problema. A fala seguinte, registrada no fórum, demonstra muito bem essa concepção: 
"Galera, tô meio (completamente) perdida, mas a gente se encontra! Preciso da ajuda de vocês pra além de entender o funcionamento, começar a fazer nosso trabalho. Vamos dividir as tarefas e claro, compartilhar as ideias, sugerir novas, enfim. Pensei em marcarmos pessoalmente na minha casa ou na facul mesmo, uma conversa pra decidirmos melhor como vão ser as coisas e começar a postar aqui nosso trabalho. Beijão" (A31).

Para a estudante A31, a situação gerou um problema genuíno, tendo em vista que foi responsável por manifestar um estado de perplexidade ( "completamente perdida") aliado ao anseio em livrar-se dessa condição ("Preciso da ajuda de vocês pra começar a fazer nosso trabalho"). Sobre a postura de um indivíduo diante de um problema, Machado et al. (2016, p. 26) argumentam: “Ao se problematizar o conceito espontâneo dos estudantes, é possível atingir maiores níveis de generalização. O estudante passa a olhar o objeto complexo em estudo (situação real) de forma mais elaborada".

Quando os estudantes se deparam com situações problemáticas, eles buscam fazer uso do repertório intelectual de que dispõem no momento, mesmo que esse repertório seja inconsistente inicialmente. Dessa maneira, estabelecer conexões entre o conteúdo de aprendizagem e os conhecimentos que o indivíduo já possui é uma parte fundamental das metodologias educacionais ancoradas na resolução de problemas. A fala da estudante A02, ao ser questionada se havia adquirido conhecimento mediante a resolução do problema, confirma essa visão: "Adquirir não seria a palavra exata, e sim, usar os [conhecimentos] que eu já tinha e estavam enferrujando (como para bolar os textos, e falar sobre o que já sabia antes)" (A02). A expressão da estudante A02 demonstra que a resolução do problema promoveu a ativação dos conhecimentos já existentes em sua estrutura cognitiva e permitiu que a aprendizagem fizesse sentido para ela. Como assinala Miras (2006), o potencial significativo de uma aprendizagem reside nas relações com sentido que o estudante é capaz de estabelecer entre o que ele já conhece e o que lhe é apresentado como conteúdo de aprendizagem.

Ainda no que se refere à importância dos conhecimentos prévios para a resolução de problemas no POPBL, podemos observar na Tabela 1, criada por meio do cruzamento entre questões do questionário que, para os estudantes, o modelo atual em que a escola está amparada não considera relevante os conhecimentos que eles já possuem e seus interesses, além disso, a maioria desses mesmos estudantes entende que a resolução de problemas mediante a elaboração de um projeto é algo bom ou excelente.

Tabela 1: Relação entre conhecimentos prévios e a resolução de problemas.

\begin{tabular}{|c|c|c|c|c|}
\hline & \multicolumn{2}{|c|}{$\begin{array}{l}\text { Um dos grandes problemas das } \\
\text { escolas atuais é que não levam } \\
\text { em consideração os interesses } \\
\text { e conhecimentos prévios dos } \\
\text { estudantes. }\end{array}$} & \multirow[t]{2}{*}{ Total } \\
\hline & & Concordo & Não Tenho Opinião & \\
\hline \multirow{3}{*}{$\begin{array}{l}\text { O que você acha de a resolução de } \\
\text { problemas ser realizada mediante } \\
\text { a elaboracão de um projeto? }\end{array}$} & Bom & $50 \%$ & 0 & $50 \%$ \\
\hline & Excelente & $25 \%$ & 0 & $25 \%$ \\
\hline & Regular & $18,75 \%$ & $6,25 \%$ & $25 \%$ \\
\hline \multicolumn{2}{|c|}{ Total } & $93,75 \%$ & $6,25 \%$ & $100 \%$ \\
\hline
\end{tabular}

Fonte: Elaborado pelo autor. 
É importante acrescentar que, no início do processo POPBL, a perplexidade intelectual frente aos problemas não era entendida como uma etapa para a investigação ou para a ativação dos conhecimentos prévios. Essa visão foi mudando à medida que os estudantes se familiarizavam com o processo de resolução de problemas. O diálogo publicado no fórum denota essa familiaridade com as incertezas despertadas pelo segundo problema:

— "Gente, não tem nada certo em relação aos FATOS E PLANO DE AÇÃO, vamos começar a produzir essas partes! Quem tiver ideias ou questões de aprendizagem também serve!" (A06).

— "aah acho que nos fatos temos que colocar algo do tipo assim: como os estudantes ja tinha contato com a tecnologia, resolvemos trabalhar com planilha no excel. .. E como as vezes algum estudante nunca ouviu falar sobre o $\mathrm{pH}$, resolvemos dar uma explicação básica .. algo assim do tipo, mas melhor elaborada" (A39).

Por conseguinte, as dúvidas foram legitimadas como parte do processo de investigação intelectual:

— "Vamos começar então? O que temos:1) Pesquisar em sites indicados pelo Professor. 2) Consultar dados industriais. 3) Estudar apostilas de ensino básico do Excel" (A06).

— "acho que está ótimo, e se preciso, consultar algum professor" (A39).

— "Professor de informática?" (A06).

— "de química, sobre alguma dúvida em relação a essa matéria" (A39).

Desse modo, é possível inferir que a abordagem "Blended Online POPBL" desenvolve a habilidade investigativa na resolução de problemas, já que, de acordo com Dewey (1950), uma situação indeterminada se faz problemática no processo de ser submetida à investigação com o objetivo de transformá-la, mesmo que de forma parcial, em uma situação determinada.

A reflexão que resulta da investigação tem como estímulo, muitas vezes, uma situação indeterminada, mas nem todas as situações indeterminadas provocam a investigação reflexiva. As falas dos estudantes atestam que para haver um empenho significativo em resolver uma situação problemática há que se encontrar nela algo em comum com suas próprias vidas. Nesse sentido, o estudante A20 sugeriu, em mensagem enviada ao fórum, utilizar os conteúdos da disciplina de Química Geral e Experimental no projeto que o grupo estava desenvolvendo: "pessoas lindas do bottom of my heart. Estive pensando em fazer um software que faz simulações das reações de química qualitativa, como as aulas 9 e 10 de Química Geral e experimental, para determinar qual é o ion em questão" (A20).

Quando o estudante A20 fala de usar os conteúdos da disciplina que ele e os colegas estão estudando, ele fala de suas vivências, observa relações entre o que é conhecido e os novos desafios que se apresentam o que, segundo Dewey (1959b, p. 172), é essencial para a reflexão:

Grande parte da arte da educação reside em tornar a dificuldade dos novos problemas suficientemente grande para dar trabalho ao espírito, mas suficientemente pequena para 
que, ao lado da confusão natural originada pelos seus elementos novos, existam pontos claros e familiares, de que possam brotar sugestões utilizáveis.

Além da investigação, a habilidade de resolver problemas também possui um caráter metódico, ou seja, um planejamento de ações. Para Pozo (1998), a solução de um problema exige passos, como compreender o problema, conceber um plano para sua resolução, executar o plano e analisar os resultados obtidos. Sobre os passos para a solução dos problemas, a estudante A06 relatou no fórum: "Então A23 resumindo, tem-se duas ideias que foram as que eu postei quase agora e duas questões de aprendizagem. Por enquanto nenhum plano de ação, então qualquer ideia vai ser acrescentada de acordo com o quadro referencial" (A06). Ao contribuir para o preenchimento do Quadro Referencial (Figura 1), a estudante A06 seguiu um método que incluía a compreensão do problema mediante ideias para sua resolução, determinação do que deveria aprender e elaboração do plano de ação para busca de informações.

Figura 1: Quadro Referencial elaborado pelo Grupo 4 para a resolução do $2^{\circ}$. problema.

\begin{tabular}{|c|c|c|c|}
\hline \multicolumn{4}{|l|}{ Definição do Problema: } \\
\hline \multicolumn{2}{|c|}{ Com Relação ao Problema } & \multicolumn{2}{|c|}{ Com Relação ao Grupo } \\
\hline Ideias & Fatos & Questões de Aprendizagem & Plano de Ação (Pesquisa) \\
\hline $\begin{array}{l}\text { Essa coluna é destinada às ideias } \\
\text { propostas pelos integrantes do grupo } \\
\text { para resolver o problema. Não pode } \\
\text { haver censura às ideias propostas. } \\
\text { Deve ser registrado o maior número } \\
\text { de ideias possiveis. }\end{array}$ & $\begin{array}{l}\text { Procure, no problema, evidências } \\
\text { para suas ideias (atividade com } \\
\text { discussão). }\end{array}$ & $\begin{array}{l}\text { Registre conceitos relevantes para } \\
\text { dar solução ao problema. } \\
\text { Devem ser registrados nessa } \\
\text { coluna todos os conceitos que o } \\
\text { aluno do grupo tutorial deverá } \\
\text { pesquisar na fase de estudo } \\
\text { individual. }\end{array}$ & $\begin{array}{l}\text { Planejamento de como o grupo irá } \\
\text { buscar responder às questōes de } \\
\text { aprendizagem (quem, onde, o que } \\
\text { ou como pesquisar para responder } \\
\text { as questôes da coluna "questōes de } \\
\text { aprendizagem") }\end{array}$ \\
\hline $\begin{array}{l}\text { - Elaborar aula de introdução aos } \\
\text { assuntos: ácido, bases e PH } \\
\text { - Explicitar o conceito de PH a } \\
\text { partir de experimento caseiro. } \\
\text { - Utilizar vídeos de experimentos } \\
\text { com o suco do repolho roxo, } \\
\text { exemplificando alguns alimentos } \\
\text { escolhidos a fim de auxiliar no } \\
\text { entendimento da matéria. } \\
\text { - Entregar fitas indicadoras de Ph } \\
\text { para os alunos individualmente } \\
\text { observarem os resultados de } \\
\text { acordo com o alimento escolhido } \\
\text { por si (atividade de } \\
\text { memorização). }\end{array}$ & $\begin{array}{l}\text { - O público-alvo (alunos em } \\
\text { questão) é habituado com } \\
\text { tecnologia. } \\
\text { - O programa Excel condiz com o } \\
\text { contexto cultural dos alunos. } \\
\text { - A ausência de conhecimento do } \\
\text { conteúdo programático. } \\
\text { - Falta de interesse pelas aulas } \\
\text { por parte do corpo discente. }\end{array}$ & $\begin{array}{l}\text { - O comportamento de ácido e } \\
\text { bases. } \\
\text { - O indicador de PH } \\
\text { - Execução de fórmulas } \\
\text { associadas aos dados tabelados } \\
\text { no Excel. }\end{array}$ & $\begin{array}{l}\text { - Pesquisar em sites indicados } \\
\text { pelo Professor. } \\
\text { - Consultar dados industriais. } \\
\text { - Consulta a um professor de } \\
\text { química sobre o conteúdo } \\
\text { (ácidos, bases e indicador de } \\
\text { Ph). } \\
\text { - Estudar apostilas de ensino } \\
\text { básico do Excel. }\end{array}$ \\
\hline Líder: & Redator: & $\begin{array}{l}\text { Mediador das discussões no } \\
\text { Fórum: }\end{array}$ & Membro(s): \\
\hline
\end{tabular}

Fonte: Elaborado pelo autor.

Delisle (2000, p. 36) considera que o Quadro Referencial para o entendimento do problema e delineamento do projeto deve ser elaborado porque:

Ele assegura que o trabalho dos estudantes tenha um fundamento adequado e que nenhum dos elementos essenciais fique esquecido. A estrutura é a chave de todo o processo da PBL, o que mostra aos estudantes como pensar ao longo da situação e como alcançar uma solução adequada. 
No tocante à importância da compreensão do problema, Pozo (1998) deixa claro que essa habilidade não se trata apenas de compreender a linguagem ou símbolos em que o problema se apresenta, mas validar a situação desse problema e se empenhar em resolvê-lo. A fala do estudante A18, publicada no fórum, demonstra a legitimação da situação problemática e seu empenho em resolvê-la:

- "Estive conversando com uma professora que me deu aula no ensino médio, que fez uma especialização em variedades étnicas mundiais, com ênfase na África, vcs devem estar se perguntando o que isso tem a ver com o problema. Bom, ela me explicou como o pessoal de regiões isoladas está se adaptando a essas "coisas" do mundo moderno. Acredito que pode ajudar no modo de elaboração do trabalho" (A18).

Polya (1945) apud Pozo (1998, p. 24) orienta que após a compreensão do problema é necessário conceber um plano para solucioná-lo: "Devemos nos perguntar qual é a distância entre a situação da qual partimos e a meta à qual pretendemos chegar, e quais são os procedimentos mais úteis para diminuir essa distância”. Após delinear o plano de ação para resolver o problema, o passo seguinte é colocá-lo em execução. A autoavaliação da estudante A39 ilustra que o problema foi resolvido, após a execução do plano: "Como verá no meu Relatório Individual, elaboramos passo a passo para a solução do problema, para chegar num resultado verídico" (A39).

Normalmente, executar o plano de ação faz que o problema se transforme em outro, na medida em que variam os elementos conhecidos e desconhecidos (POZO, 1998). Daí o uso do termo "resolução de problemas" em vez de "solução de problemas", pois na execução do plano de ação o problema se transforma e deparamos com um novo problema e com a necessidade de novos planos para resolvê-lo. Em seu relatório, a estudante A23 revela que a ideia inicial registrada no plano de ação sofreu modificações quando o grupo refletiu sobre sua execução:

— "Inicialmente, pensávamos em fazer um jogo, mas não qualquer jogo, um modelo de jogo que estivesse de acordo com a realidade dos estudantes, que eles já conhecessem as regras do mesmo tornando mais fácil ainda o entendimento de como surgiu e como funciona um computador. Porém somente o jogo, para nós, ficou muito vago e voltamos novamente à estaca zero pensando em algo que complementasse o jogo" (A23).

A partir do plano de ação, o projeto desenvolvido por um dos grupos buscou resolver o problema mediante um material pedagógico que abarcou uma diversidade de atividades em sala de aula, articulando a teoria e a prática. Os materiais produzidos pelo grupo incluíam: um jogo da memória, um gibi e uma lenda adaptada para o ensino e aprendizagem de componentes do computador (Figura 2). 
Figura 2: Projeto elaborado por um dos grupos para a resolução do $1^{\circ}$. problema.

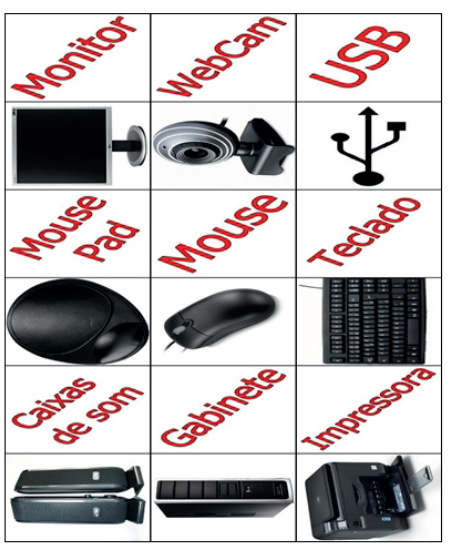

Jogo da Memória

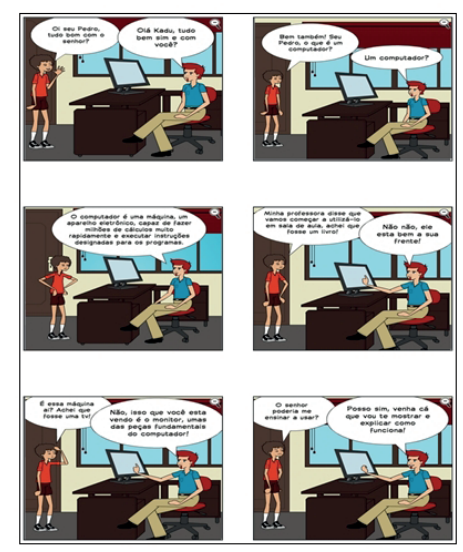

Gibi

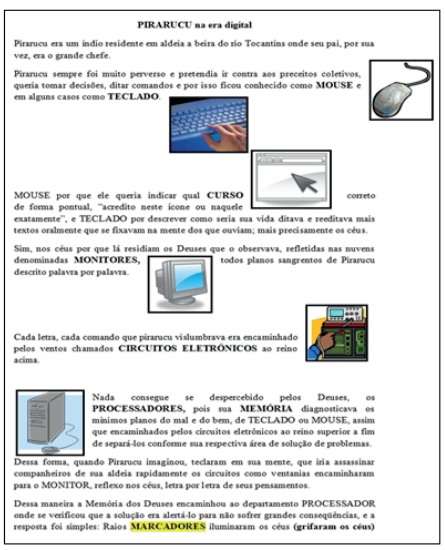

Lenda Adaptada

Fonte: Elaborado pelo autor.

O processo de resolução de um problema chega ao seu término quando a solução obtida é comparada com o objetivo definido, convém salientar que a análise da solução obtida pode ocorrer em diferentes momentos ao longo do processo de resolução dos problemas (POZO, 1998). Acerca da última habilidade requerida na resolução de problemas, podemos destacar o texto do relatório da estudante A39: "Os resultados obtidos foram anotados e analisados cuidadosamente, para saber se o nosso projeto foi satisfatório, e os dados nos surpreenderam, pois superou as nossas expectativas". A expressão da estudante A39 permite inferir que, mediante uma visão retrospectiva dos resultados, o projeto elaborado pelo grupo excedeu positivamente a meta estabelecida, além disso, a fala revela um rigor metodológico para avaliar o sucesso da resolução do problema. O relatório da estudante A23 também demonstra que o projeto desenvolvido foi alvo de reflexão tanto para a resolução do problema quanto para agregar conhecimento à estudante: "Na minha concepção esse trabalho atingiu uma meta maior que a esperada. Foi muito trabalho criar esse projeto, mas ao mesmo tempo muito gratificante" (A23).

Assim, inferimos que os estudantes melhoraram suas habilidades procedimentais no que se refere à resolução de problemas, uma vez que a abordagem Blended Online POPBL possibilitou compreender o problema, conceber um plano de ação para resolvê-lo, executar o plano e analisar as estratégias utilizadas. Todo esse processo desenvolveu nos estudantes habilidades para abordar e solucionar um problema usando a tecnologia, ou seja, foi possível ao estudante "ter um espírito inovador, de adaptação a novos problemas, conseguindo interagir melhor com a tecnologia ao resolvê-los", pondera A31 em resposta ao questionário.

\section{CONSIDERAÇões FINAIS}

Por meio deste estudo, conclui-se que a abordagem Blended Online POPBL, por apresentar situações desafiadoras aos estudantes de um curso de licenciatura, pode ser entendida como uma poderosa aliada para despertar, estimular e manter o interesse dos estudantes 
no tocante à aprendizagem de conteúdos necessários à resolução de problemas associados à prática docente. A resolução dos problemas por meio do desenvolvimento de projetos permitiu aos estudantes irem além da aprendizagem mecânica de conteúdos relacionados às TDIC, pois a aspiração em desenvolver um projeto que contemplasse a resolução do problema articulou de forma harmoniosa a capacidade técnica de usar as ferramentas tecnológicas com os conhecimentos conceituais, possibilitando o desenvolvimento de um futuro professor mais criterioso com seu repertório de conhecimentos e mais alinhado com sua futura atuação profissional. A abordagem Blended Online POPBL possibilitou ao estudante estabelecer uma conexão significativa entre sua prática profissional e o conteúdo de estudo mediante situações estimulantes e problematizadoras.

A partir dos resultados obtidos com esta pesquisa, é possível concluir que o componente mais importante de uma metodologia ativa problematizadora, neste caso o POPBL, não é o resultado final que ela possa prover, mas o próprio processo de resolução de problemas, mediante o qual os estudantes aprendem não apenas os conteúdos conceituais, mas também a se tornarem autônomos e ativos, características exigidas na sociedade contemporânea. Trata-se de uma visão educacional que considera a aquisição de conhecimentos conceituais atrelada à aquisição de conhecimentos procedimentais e atitudinais, ou seja, é uma perspectiva que rompe com a visão tecnicista ou conteudista em favor de competências mais amplas.

A partir dessa premissa, é fundamental haver uma criteriosa reflexão para determinar a importância dos projetos no POPBL. Evidentemente, o desenvolvimento de projetos confere um status de utilidade à resolução dos problemas e é um elemento essencial para avaliar o domínio das competências vinculadas à resolução de um problema, mas há que se ter cuidado para que o projeto em si não se torne mais relevante que o processo de aprendizagem. Embora possa parecer clichê argumentar que o caminho é mais enriquecedor que a chegada, é importante que essa visão seja compartilhada por estudantes e professores, pois há uma grande chance de tanto os estudantes quanto os professores darem maior ênfase ao produto final em detrimento dos ganhos obtidos no processo de aprendizagem.

Assim, em metodologias ativas, é imprescindível que o professor tenha o cuidado de não utilizar a técnica de eleger um projeto considerado muito bom e o tomar como referencial para a avaliação dos outros estudantes ou grupos. O professor deve fundamentar sua avaliação do desempenho do estudante na relação entre o produto final de um projeto e o processo de aprendizagem que culminou em sua realização. Nesse sentido, a abordagem Blended Online POPBL representa uma perspectiva educacional que estabelece que boa parte de seu processo seja registrado ou explicitado, por exemplo, no Quadro Referencial e nas discussões em grupo registradas nos ambientes online.

Para futuros pesquisadores que tenham a intenção de utilizar e analisar abordagens semelhantes ao Blended Online POPBL em instituições tradicionais, é recomendado que o façam em disciplinas cujo conteúdo programático esteja organizado por competências, ou seja, que esteja especificado o que se espera do estudante em termos de conhecimentos, habilidades e atitudes em determinada área do conhecimento. Nesse caso, é possível apresentar aos estudantes situações-problemas abertas que possibilitem propor várias soluções na forma de projetos. Entretanto, se o conteúdo programático da disciplina for bastante 
rígido, focado mais nos conteúdos que nas competências, o uso de situações-problemas essencialmente abertas pode não ser o mais indicado. Nesse caso, para garantir que todo conteúdo programático da disciplina seja estudado pelos estudantes na resolução dos problemas, deve-se optar por uma metodologia ativa que faça uso de situações-problemas semiestruturadas e que seja também centrada em projetos.

A modalidade Blended Learning como complemento às aulas presenciais se adapta muito bem a um modelo de aprendizagem ancorada na resolução de problemas e desenvolvimento de projetos em razão das similitudes epistemológicas que possuem, mas também por razões de ordem mais prática como feedback imediato, ritmo de estudo mais personalizado a cada estudante, registro da maior parte das etapas do processo de resolução de problemas e desenvolvimento de projetos. Essas características potencializam os encontros presenciais no sentido da colaboração, uma vez que, diferente do POPBL apenas presencial, as informações levantadas durante a fase de estudo individual são socializadas e discutidas em tempo real no AVA e em outros ambientes online. Sugerimos, assim, que em uma modalidade Blended Learning, os estudantes se encontrem presencialmente antes das sessões online do POPBL, para que partilhem a sensação de perceber seus pares como membros do grupo. Assim, para que uma abordagem Blended Online POPBL tenha sucesso, o contato pessoal entre os estudantes é essencial e deve ser estimulado.

Por fim, o que está claro é que a abordagem Blended Online POPBL possibilitou que a matéria de estudo da disciplina fosse contemplada de modo a fazer que os estudantes desenvolvessem uma postura mais ativa frente aos problemas da sua futura profissão e frente à aprendizagem dos conteúdos necessários à sua resolução. Está claro também que no quesito colaboração, a abordagem Blended Online POPBL é bastante promissora, uma vez que o fluxo e a qualidade de comunicação entre os estudantes fazem uso do melhor de dois ambientes, o presencial e o online.

\section{REFERÊNCIAS}

AL-DOUS, K. K.; SAMAKA, M. The design and delivery of hybrid PBL sessions in Moodle. International Journal of Education and Information Technologies. Volume 9, 2015. Disponível em: http://www.naun.org/main/NAUN/educationinformation/2015/ a282008-149.pdf. Acesso em: 20 nov. 2016.

BARDIN, L. Análise de Conteúdo. Edição Revista e Actualizada. Lisboa, Portugal: Edições 70, 2009.

BRASIL. Diretrizes Curriculares Nacionais para os Cursos de Química. Brasília: MEC. 2001. Disponível em: http://portal.mec.gov.br/sesu/arquivos/pdf/130301Quimica. pdf. Acesso em: 3 nov. 2014.

BRASIL. Ministério Da Educação. Portaria n. ${ }^{0}$ 1.428, de 28 de dezembro de 2018. Disponível em: http://abmes.org.br/arquivos/legislacoes/Portaria1428.pdf. Acesso em: 31 mar. 2019. 
BRUNER, J. Uma Nova Teoria da Aprendizagem. Tradução: Norah Levy Ribeiro. Rio de Janeiro: Edições Bloch, 1969.

CAPRARA, A. A Construção Narrativa de Problemas. In: MAMEDE, Silvia; PENAFORTE, Júlio César (Orgs.). Aprendizagem baseada em problemas: anatomia de uma nova abordagem educacional. São Paulo: Hucitec/ESP-CE, 2001.

CHEN, W.; LOOI, C. K. Measuring process and outcome of the scientific argumentation in a CSCL environment. Proceedings of the 25th International Conference on Computers in Education. 2017. Disponível em: https://repository.nie.edu.sg/bitstream/10497/19458/1/ ICCE-2017-139.pdf. Acesso em 12 abr. 2019.

CSAPÓ, B; FUNKE, J. The development and assessment of problem solving in 21 st-century schools. In: CSAPÓ, Ben; FUNKE, Joachin (Orgs.). The Nature of Problem Solving: Using Research to Inspire 21st Century Learning. OECD Publishing, Paris, 2017. Disponível em: http://publicatio.bibl.u-szeged.hu/11201/1/2017 Csapo Funke NatureOfProblemSolving.pdf. Acesso em: 16 abr. 2019.

DELISLE, R. Como Realizar a Aprendizagem Baseada em Problemas. Lisboa, Portugal: Edições ASA, 2000.

DEWEY, J. Como Pensamos. São Paulo: Companhia Editora Nacional, 1959a.

DEWEY, J. Democracia e Educação: introdução à filosofia da educação. Tradução por Godofredo Rangel, Anísio Teixeira, 3. ed. São Paulo: Nacional, 1959b.

DEWEY, J. Logica: Teoria de La Investigación. México: Editora Fondo de Cultura Económica, 1950.

FONT, A. Las líneas maestras del aprendizaje por problemas: Guide lines form Problem Based Learning. Revista Interuniversitaria de Formación del Profesorado 18 (1), p. 7995. ISSN 0213-8464. 2004. Disponível em: http://www.aufop.com/aufop/uploaded_files/ articulos/1219255894.pdf. Acesso em: 17 nov. 2016.

FORRESTER, V. Problem-based Learning: a Problem with Education? Hong Kong Teachers. Centre Journal. V. 3, 2004. Disponível em: http://edb.org.hk/HKTC/download/journal/j3/5.pdf. Acesso em: 10 abr. 2019.

HÄKKINEN, P.; JÄRVELÄ, S.; MÄKITALO-SIEGL, K.; AHONEN, A.; NÄYKKI, P.; VALTONEN, T. Preparing teacher-students for twenty-first-century learning practices (PREP 21): a framework for enhancing collaborative problem-solving and strategic learning skills. Teachers and Teaching. Vol. 23, Issue 1, 2017. Disponível em: https://www. tandfonline.com/doi/full/10.1080/13540602.2016.1203772. Acesso em: 2 abr. 2019.

HORN, M. B.; STAKER, H. Blended: usando a inovação disruptiva para aprimorar a educação. Porto Alegre: Penso, 2015. 
HUNG, W. All PBL Starts Here: The Problem. Interdisciplinary Journal of ProblemBased Learning, v. 10, n. 2, 2016. Disponível em: https://pdfs.semanticscholar.org/6c91/ aab5c2c86db60eddb2f226d809a0463ffa73.pdf. Acesso em: 14 abr. 2019.

JONASSEN, D. H. Computadores, ferramentas cognitivas: Desenvolver o pensamento crítico nas escolas. Porto, Portugal: Porto Editora, 2000.

KURTZ, F. D.; DA SILVA, D. Tecnologias de Informação e Comunicação (TIC) como Ferramentas Cognitivas na Formação de Professores. Revista Contexto \& Educação, v. 33, n. 104, p. 5-33, 21 fev. 2018. Disponível em: https://www.revistas.unijui.edu.br/index. php/contextoeducacao/article/view/6935. Acesso em: 3 abr. 2019.

LAND, S. M.; OLIVER, K. M. Open Learning Environments. In: SEEL, Norbert M. (Orgs.). Encyclopedia of the Sciences of Learning. Publisher: Springer, 2012. Disponível em: https://www.researchgate.net/publication/279205236 Open_Learning_Environments. Acesso em: 3 abr. 2019.

LIMA, J. R.; CAPITÃO, Z. E-Learning e E-Conteúdos: Aplicações Das Teorias Tradicionais e Modernas de Ensino e Aprendizagem à Organização e Estruturação de E-Cursos. Lisboa. Portugal. Editora: Centro Atlântico, 2003.

MACHADO, A. R.; MARQUES, C. A.; SILVA, R. M. G. Sentidos e significados de problema e problematização em um processo de (re)planejamento coletivo de uma situação de estudo. Ciência \& Educação. Vol. 22, núm. 1, jan./mar. 2016. Disponível em: http://www. redalyc.org/pdf/2510/251044327003.pdf. Acesso em: 5 dez. 2018.

MASETTO, M. T. PBL na Educação? In: Endipe, 12, Curitiba. Anais. Curitiba: Editora Universitária Champagnat, v. 2, p. 181-189, 2004.

MIRAS, M. Um ponto de partida para a aprendizagem de novos conteúdos: os conhecimentos prévios. In: COLL, César et al. (Org.). O construtivismo na sala de aula, 6. ed. São Paulo: Editora Ática, 2006.

MOESBY, E. Perspectiva Geral da Introdução e Implementação de um Novo Modelo Educacional Focado na Aprendizagem Baseada em Projetos e Problemas. In: ARAÚJO, Ulisses F. \& SASTRE, Genoveva (Orgs). Aprendizagem Baseada em Problemas no Ensino Superior. São Paulo: Summus Editorial, 2009.

MORAN, J. M. Mudando a educação com metodologias ativas. In: Convergências Midiáticas, Educação e Cidadania: aproximações jovens. Coleção Mídias Contemporâneas, 2015. Disponível em: http://www2.eca.usp.br/moran/wpcontent/uploads/2013/12/mudando moran.pdf. Acesso em: 30 mar. 2019.

MORAN, J. M.; ARAÚJO FILHO, M.; SIDERICOUDES, O. A ampliação dos vinte por cento a distância: estudo de caso da Faculdade Sumaré - SP. $\mathbf{1 2}^{\mathbf{0}}$. Congresso Internacional 
de Educação a Distância - ABED. Florianópolis, SC, 2005. Disponível em: http://www. abed.org.br/congresso2005/por/pdf/172tcc3.pdf. Acesso em: 5 fev. 2014.

OGUZ-UNVER, A.; ARABACIOGLU, S. Overviews on Inquiry Based and Problem Based Learning Methods. Western Anatolia Journal of Educational Sciences (WAJES). Dokuz Eylul University Institute, Izmir, Turkey. ISSN: 1308-8971. 2011. Disponível em: http://webb.deu.edu.tr/baed/giris/baed/ozel_sayi/303-310.pdf. Acesso em: $1^{\circ}$. fev. 2017.

PEIRCE. C. S. A fixação das crenças. In: Semiótica e filosofia. São Paulo: Cultrix, Editora da USP, p. 71-92, 1975.

POZO, J. I. A Solução de Problemas. Aprender a resolver, resolver para aprender. Porto Alegre: Artes Médicas, 1998.

PRETTO, N. L.; PASSOS, M. S. C. Formação ou Capacitação em TIC? Reflexões sobre as Diretrizes da UNESCO. Revista Docência e Cibercultura. Rio de Janeiro, v. 1, n. 1, set. 2017. Disponível em https://www.e-publicacoes.uerj.br/index.php/re-doc/article/ view/30490/23512. Acesso em: 3 abr. 2019.

QVIST, P. Democratic elements in group and project organized PBL: democratic skills and buildung via project organized problem based learning in groups in the Aalborg Model. Results from a pilot investigation. Connecting learning to the real world: International Conference PBL 2006 ABP. Pontificia Universidad Católica del Perú, 2006. Disponível em: http://vbn.aau.dk/files/4852131/PQ PBL_2006_ABP.pdf. Acesso em: 14 jul. 2016.

RIBEIRO, L. R. C. Aprendizagem baseada em problemas (PBL): uma experiência no ensino superior. São Carlos: EdUFSCar, 2008.

SALOMON, G.; PERKINS, D. N.; GLOBERSON, T. Coparticipando en el conocimiento: la ampliación de la inteligencia humana con las tecnologías inteligentes. Revista CL \& E: Comunicación, lenguaje y educación. ISSN 0214-7033, № 13, p. 6-22. 1992. Disponível em: http:/dialnet.unirioja.es/descarga/articulo/126248.pdf. Acesso em: 7 set. 2014.

SAVIN-BADEN, M. The challenge of using problem-based learning online. In ProblemBased Learning Online. Org. Maggi Savin-Baden \& Kay Wilkie. Maidenhead, Berkshire, England: McGraw Hill, p. 3-13. 2006. Disponível em: https://www.mheducation. co.uk/openup/chapters/0335220061.pdf. Acesso em: 10 ago. 2016.

SILBY, B. Is Problem-Based Learning Superior to Direct Instruction? Journal of Education, 2013. Disponível em: https://philarchive.org/archive/SILIPL. Acesso em: 10 abr. 2019.

SOUSA, S. O. Blended Online POPBL: Uma Abordagem Blended Learning para uma Aprendizagem Baseada em Problemas e Organizada em Projetos, 2015, 294s. Tese (Doutorado em Educação) - Faculdade de Ciências e Tecnologia, UNESP - Universidade 
Estadual Paulista, Presidente Prudente, 2015. Disponível em: http://www2.fct.unesp.br/ pos/educacao/teses/2015/dr/sidinei_sousa.pdf. Acesso em: 22 jun. 2018.

SOUSA, S. O.; SCHLÜNZEN JUNIOR, K. A contribuição de um Ambiente Virtual de Aprendizagem para potencializar a colaboração no Desenvolvimento da Aprendizagem Baseada em Problemas. Revista El Hombre y la Máquina. Nº. 40, 2012. Disponível em: http://www.redalyc.org/articulo.oa?id=47826850005. Acesso em: 20 abr. 2019.

SOUZA, K. R.; KERBAUY, M. T. M. Abordagem quanti-qualitativa: superação da dicotomia quantitativa-qualitativa na pesquisa em educação. Revista Educação e Filosofia, Uberlândia, v. 31, n. 61, jan./abr. 2017. Disponível em: http://www.seer.ufu.br/index.php/ EducacaoFilosofia/article/view/29099. Acesso em: 10 mar. 2018.

STROBEL, J.; VAN BARNEVELD, A. PBL effectiveness, tensions, and practitioner implications. In: WALKER, A.; LEARY, H.; HMELO-SILVER, C. E.; ERTMER, P. A. (Org). Essential Readings in Problem-based Learning. Purdue University Press, 2015.

VALENTE, J. A. Síntese do Projeto Original “O Laptop Educacional e a Educação Baseada na Investigação: do estudo de fatos científicos para o fazer científico". In: VALENTE, J. A.; MARTINS, M. C.; BARANAUSKAS, M. C. C. (Org.). Aprendizagem baseada na investigação. Campinas, SP: UNICAMP/NIED, 2014.

\section{Dados do AUtor}

\section{Sidinei Oliveira Sousa}

Doutor em Educação pela Universidade Estadual Paulista. Professor no Centro Estadual de Educação Tecnológica Paula Souza e na Faculdade de Informática de Presidente Prudente/ SP-Brasil.sidneysiamf@gmail.com

Submetido em:30-8-2018

Aceito em: 30-5-2020 